\title{
Route Effects in I-ECAP of AZ31B Magnesium Alloy
}

\author{
Michal Gzyl ${ }^{1, a}$, Andrzej Rosochowski ${ }^{1, b}$, Evgenia Yakushina ${ }^{2, c}$, \\ Paul Wood ${ }^{2, d}$, Lech Olejnik ${ }^{3, e}$ \\ ${ }^{1}$ Design, Manufacture and Engineering Management, University of Strathclyde, \\ James Weir Building, 75 Montrose Street, Glasgow G1 1XJ, United Kingdom \\ ${ }^{2}$ Advanced Forming Research Centre, University of Strathclyde, \\ 85 Inchinnan Drive, Renfrew PA4 9LJ, United Kingdom \\ ${ }^{3}$ Institute of Manufacturing Processes, Warsaw University of Technology, \\ ul. Narbutta 85, 02-524 Warsaw, Poland \\ amichal.gzyl@gmail.com, ba.rosochowski@strath.ac.uk, cevgenia.yakushina@strath.ac.uk, \\ dpaul.wood@strath.ac.uk, ${ }^{\mathrm{e}}$ l.olejnik@wip.pw.edu.pl
}

Keywords: magnesium alloys, equal channel angular pressing, ultrafine grained metals.

\begin{abstract}
An AZ31B wrought magnesium alloy was processed by incremental equal channel angular pressing (I-ECAP) using routes $A$ and $\mathrm{B}_{\mathrm{C}}$. Despite the fact that the measured grain size for both routes was very similar, the mechanical properties were different. Tensile strength was improved using route $\mathrm{A}$ comparing to route $\mathrm{B}_{\mathrm{C}}$, without ductility loss, while tension-compression anisotropy observed for route $\mathrm{A}$ was significantly suppressed when using route $B_{C}$. Moreover, billet shape evolution resulting from subsequent passes of I-ECAP was studied. Significant distortion after processing using route $\mathrm{B}_{\mathrm{C}}$ and no occurrence of such effect for route A were observed. Results of a finite element analysis showed that nonuniform strain rate sensitivity might be responsible for different billet shapes. The conclusion is drawn that processing route has a strong influence on the billet shape and mechanical properties when processing magnesium alloys by I-ECAP.
\end{abstract}

\section{Introduction}

Magnesium and its alloys have the lowest density among all metallic construction materials and the highest strength to density ratio. That makes them very promising for aerospace, automotive and electronic applications. Especially, in the automotive industry, saving weight becomes more significant due to economic and ecological reasons [1]. However, there are many challenges when trying to manufacture parts made of magnesium alloys. One of them is low ductility at room temperature. It is attributed to the hexagonal closed-packed (hcp) structure of magnesium, which is characterised by a low number of operating slip systems to enable plastic deformation.

In order to improve mechanical properties of magnesium and other metals, various thermo-mechanical processes have been proposed. Equal channel angular pressing (ECAP) [2] is the most developed severe plastic deformation process, which can be used for bulk metal billets [3]. However, the process is not widely used in industrial practice since only relatively small amount of material can be processed due to force and tool limitations. Recently, incremental ECAP (I-ECAP) has been developed by Rosochowski and Olejnik [4]. In I-ECAP, the stages of material feeding and plastic deformation are separated (Fig. 1), which reduces the feeding force significantly. The tool configuration consists of a punch working in a reciprocating manner and a die leading and feeding the material in incremental steps. As long as the feeding stroke is appropriately small, the subsequent shear zones overlap, giving a uniform strain distribution along 
the billet. I-ECAP can be used for processing long bars [5], plates [6] and sheets [7]. In order to increase process efficiency and reduce friction, a double-billet variant was proposed [8] as shown in Fig. 1.

ECAP

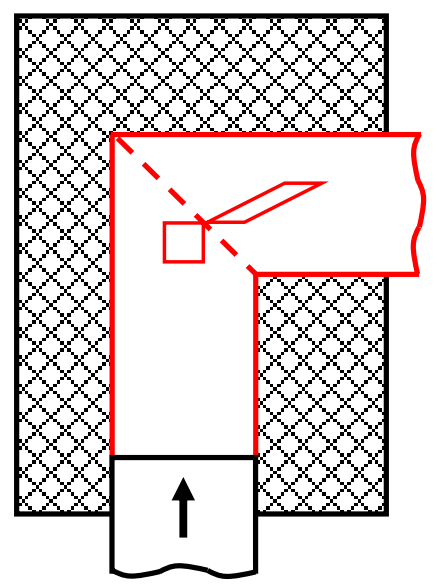

I-ECAP

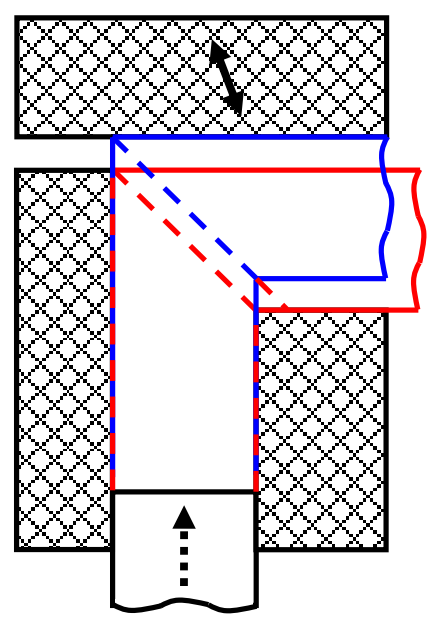

I-ECAP

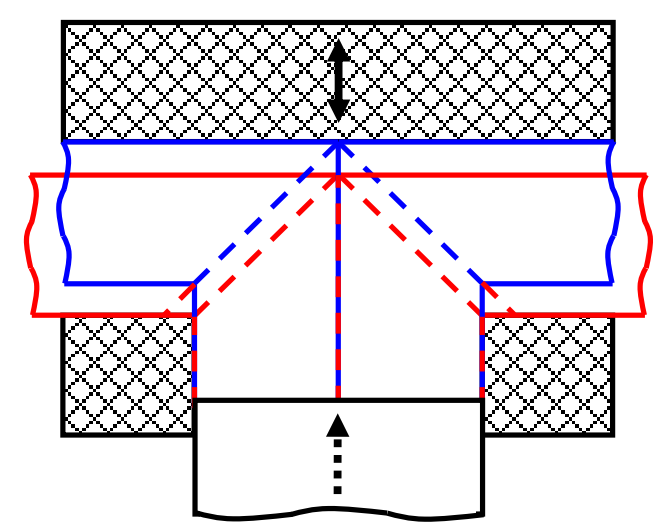

Fig. 1: Comparis on of ECAP and I-ECAP and double-billet variant of I-ECAP [5].

The metal flow in ECAP has been studied using different techniques such as visioplasticity [9], slip line theory [10] and finite element method (FEM) [11]. Nevertheless, the effect of anisotropy on flow stability was not taken into account since isotropic materials, e.g. aluminium and copper alloys, were usually examined. Recent reports on ECAP of Mg alloys show that flow homogeneity could be affected by strain softening [12] and strain rate sensitivity [13]. The former results in strain localization and leads to damage accumulation on billet surface. The latter can suppress plastic instability but also increases strain distribution inhomogeneity. Described phenomena were studied in many papers but the origin of billet distortion after subsequent passes of ECAP with different processing routes has not been thoroughly investigated.

Mechanical properties of magnesium alloys processed by ECAP are different from fcc metals. Yield strength decrease and ductility enhancement are usually observed after 4 passes $[15,16,17]$. The inverse Hall-Petch effect was also reported for AZ61 magnesium alloys in [18]. In [19], the grain size effect on yield stress during compression of AZ31 was studied. A distinctive concave shape of the flow stress curve at room temperature was attributed to twinning. It was also shown that fine grain microstructure (3-4 $\mu \mathrm{m})$ can switch deformation mechanism from twinning- to slip-dominated. This effect was observed only at elevated temperatures, whereas ECAP processing is believed to suppress twinning during compression along extrusion direction even at room temperature [20].

The goal of this work was to examine the mechanical properties of a magnesium alloy AZ31B processed by I-ECAP using routes $A$ and $\mathrm{B}_{\mathrm{C}}$. The influence of processing temperature on grain refinement and flow behaviour was also investigated. Moreover, an explanation of billet distortion observed for route $\mathrm{B}_{\mathrm{C}}$ was proposed using FE analysis. Strain rate dependent and anisotropic material description was incorporated into the FE model. The numerical prediction was compared with experimental results. Better understanding of the phenomena observed during deformation of magnesium alloys can help avoid undesirable effects such as unstable flow and fracture.

\section{Experimental procedure}


Commercially extruded AZ31B magnesium rods, $16.8 \mathrm{~mm}$ in diameter, were machined using the electro discharge machining (EDM). Bars with square cross-section $10 \times 10 \mathrm{~mm}^{2}$ and length equal to $120 \mathrm{~mm}$ were obtained. A double-billet variant of I-ECAP was realised using a $1 \mathrm{MN}$ hydraulic servo press. The billets were fed using a screw jack whose action was synchronised with the reciprocating movement of the punch (Fig 2). The punch movement followed an externally generated sine waveform with frequency 0.5 $\mathrm{Hz}$ and amplitude equal to $2 \mathrm{~mm}$. A motor driven screw jack was controlled using National Instruments hardware and software (LabVIEW). The feeding stroke was equal to $0.2 \mathrm{~mm}$.

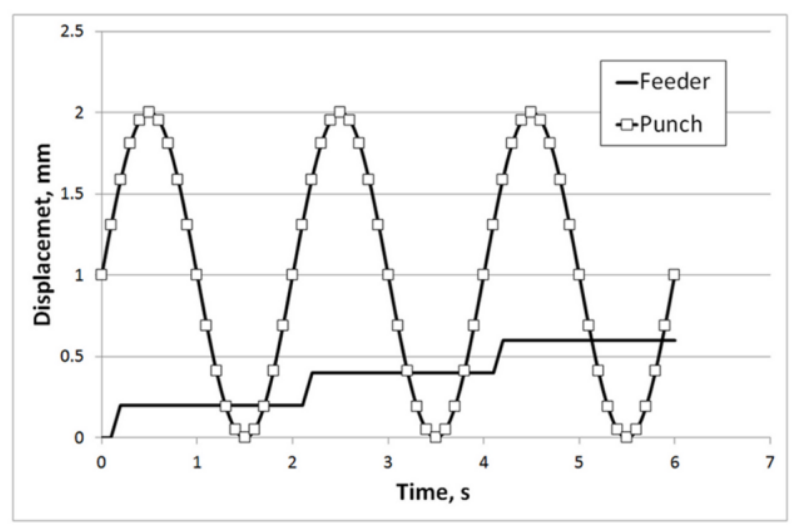

Fig. 2: Synchronised movement of punch and feeder at the initial stage of I-ECAP.

A die with $90^{\circ}$ channel angle was used to conduct four and six passes of I-ECAP. It has resulted in the total true strain of $\sim 4.6$ and $\sim 6.9$, respectively. Experiments with routes A (without rotation after subsequent passes) and $\mathrm{B}_{\mathrm{C}}$ (rotation by $90^{\circ}$ ) were carried out at $250{ }^{\circ} \mathrm{C}$ and $200{ }^{\circ} \mathrm{C}$. Samples with different processing histories were obtained:

- four passes at $250{ }^{\circ} \mathrm{C}$ using route $\mathrm{B}_{\mathrm{C}}$,

- four passes at $250{ }^{\circ} \mathrm{C}$ plus two passes at $200{ }^{\circ} \mathrm{C}$ using route $\mathrm{B}_{\mathrm{C}}$,

- four passes at $250{ }^{\circ} \mathrm{C}$ plus two passes at $200{ }^{\circ} \mathrm{C}$ using route $\mathrm{A}$.

Due to fracture occurrence, it was not possible to conduct I-ECAP at $200{ }^{\circ} \mathrm{C}$ without earlier processing at $250{ }^{\circ} \mathrm{C}$. Billets were held in the hot die for 15 minutes prior to processing in order to stabilize their temperature. Dies were heated up using electric heaters. Temperature during processing was kept constant within $\pm 2{ }^{\circ} \mathrm{C}$, based on the readings obtained from a thermocouple located near deformation zone. Molybdenum disulphide $\left(\mathrm{MoS}_{2}\right)$ was used as lubricant.

Mechanical behaviour of as-received and I-ECAPed material was investigated. Tension and compression tests were conducted on Instron 5969 testing machine with maximum load capacity $50 \mathrm{kN}$. Tests were carried out at room temperature with initial strain rate equal to $0.001 \mathrm{~s}^{-1}$. Specimens were cut out along the extrusion direction. Height and diameter of compressive specimen were $8 \mathrm{~mm}$ and $7 \mathrm{~mm}$, respectively. Round tensile samples with $2.5 \mathrm{~mm}$ diameter and strain gauge length equal to $15 \mathrm{~mm}$ were used. Microstructures of processed billets were examined using SEM.

\section{Results and discussion}

I-ECAP experiments. Shapes of billets processed by routes $A$ and $B_{C}$ are remarkably different. Rotation by $90^{\circ}$ after subsequent passes causes much bigger distortion comparing to processing without any rotation. Fig. $3 \mathrm{a}$ and $3 \mathrm{c}$ show samples after four passes of I-ECAP using routes $\mathrm{B}_{\mathrm{C}}$ and $\mathrm{A}$, respectively. It is clearly seen that sample processed by route $\mathrm{B}_{\mathrm{C}}$ did not fill the exit channel completely and distinctive curved ending is also observed. In contrast, processing using route A did not affect sample 
shape; cross-sectional dimensions after processing were the same as in the initial state. Results obtained for route A were similar to I-ECAP of aluminium alloy [5] while processing by route $\mathrm{B}_{\mathrm{C}}$ led to unsymmetrical billet shape that has not been reported before.

Moreover, an unusual pattern was observed on the billet lower surface where flow lines were revealed (Fig. 3b). Flow lines developing at an angle different from $90^{\circ}$ indicate that material flow velocity distribution is non-uniform along billet cross section. The explanation of this phenomenon will be proposed using FE analysis in the further part of the paper.

Force readings obtained from a load cell attached to the punch are plotted in Fig. 3d. The maximum force during first and fourth pass of I-ECAP drops from $\sim 33 \mathrm{kN}$ to $\sim 25 \mathrm{kN}$. The load decrease is attributed to grain refinement since smaller grains facilitate grain boundary diffusion [21].

a)

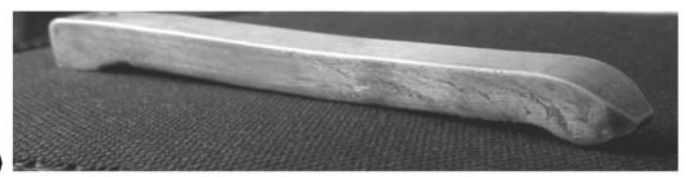

b)

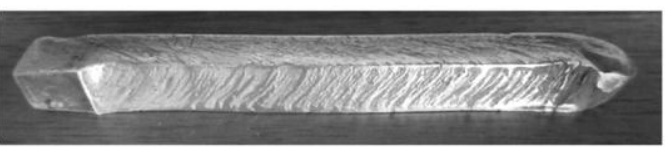

c)

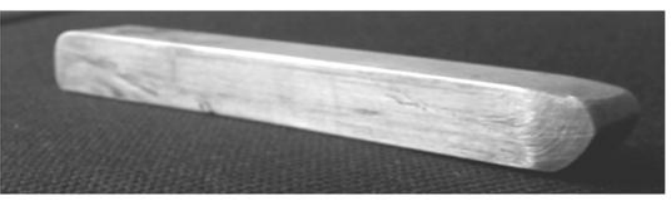

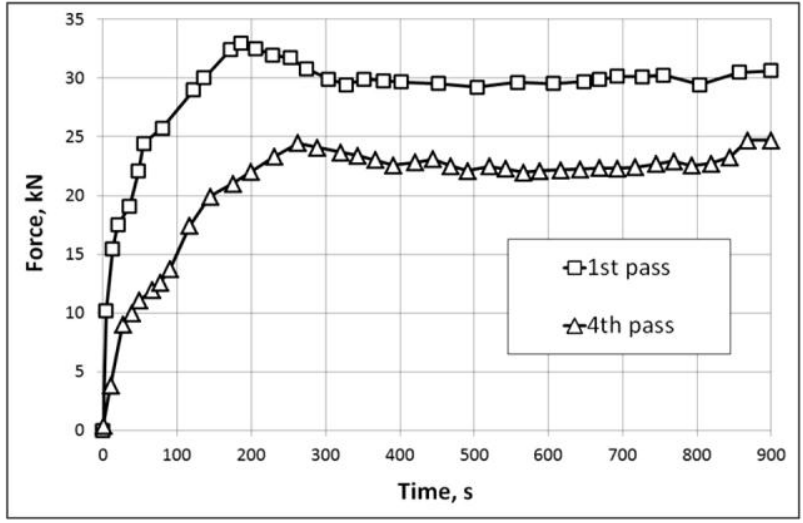

d)

Fig. 3: Results of I-ECAP: billet shape after four passes using route $B_{C}$ (a) and (b) and route $A(c)$; force readings after first and fourth pass by route $B_{C}$.

Microstructure and mechanical properties. The microstructure of as supplied material was characterised as heterogeneous with the mean grain size equal to $48 \mu \mathrm{m}$ for coarse grain regions and $5 \mu \mathrm{m}$ for fine grained regions. A remarkable grain refinement and microstructure homogenization after I-ECAP processing was observed. The mean grain size after 4 passes at $250{ }^{\circ} \mathrm{C}$ with route $\mathrm{B}_{\mathrm{C}}$ was equal to $6.2 \mu \mathrm{m}$ (Fig. 4a). Lowering the processing temperature to $200{ }^{\circ} \mathrm{C}$ in the fifth and the sixth pass resulted in further grain refinement to $2.6 \mu \mathrm{m}$ for route $\mathrm{B}_{\mathrm{C}}$ (Fig. $4 \mathrm{~b}$ ) and $2.4 \mu \mathrm{m}$ for route $\mathrm{A}$ (Fig. $4 \mathrm{c}$ ). It is concluded that temperature controls the grain refinement process while processing route has no significant effect on grain size.

a)

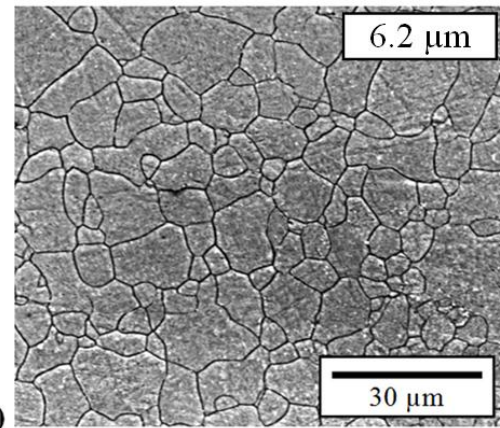

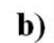

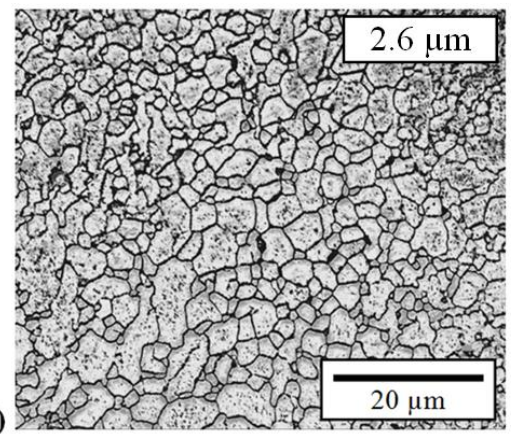

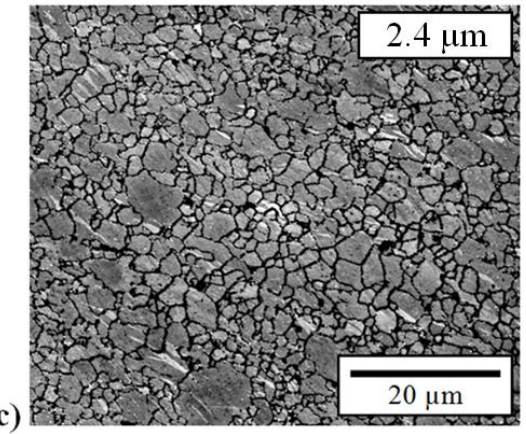

Fig. 4: SEM images showing microstructures after I-ECAP processing: 4 passes at $250{ }^{\circ} \mathrm{C}$ using route $\mathrm{B}_{\mathrm{C}}$ (a); 4 passes at $250{ }^{\circ} \mathrm{C}$ and 2 passes at $200^{\circ} \mathrm{C}$ using route $\mathrm{B}_{\mathrm{C}}(\mathrm{b}) ; 4$ passes at $250{ }^{\circ} \mathrm{C}$ and 2 passes at $200^{\circ} \mathrm{C}$ using route $\mathrm{A}$ (c). 
Although the reported grain refinement was not dependent on the route used, mechanical properties of obtained samples were significantly different. A concave shape of the compression flow stress curve (Fig. 5a) was observed for the hot extruded rod as well as for the sample processed by route A. It is a well established behaviour of magnesium alloys attributed to mechanical twinning [21]. I-ECAP processing by route $\mathrm{A}$ resulted in a slightly increased compressive strain from 0.08 to 0.1 and yield strength increase from $100 \mathrm{MPa}$ to $150 \mathrm{MPa}$. However, properties of the processed material are rather similar to the extruded rod. In contrast, route $\mathrm{B}_{\mathrm{C}}$ changes the shape of the compressive flow stress curve significantly. Ductility enhancement was observed; compressive strain rose up to 0.18. Simultaneously, the maximum stress was decreased to $\sim 250 \mathrm{MPa}$ from the initial value of $370 \mathrm{MPa}$. As a consequence of I-ECAP processing, tensile yield stress was lowered and tensile strain was increased from 0.08 to $\sim 0.22$, irrespectively of the route used (Fig. 5b). Usage of route A resulted in a tensile strength improvement by $50 \mathrm{MPa}$ comparing to route $\mathrm{B}_{\mathrm{C}}$.

Influence of billet rotation after subsequent passes on tension-compression asymmetry was also investigated. The initial material is characterised by a concave shape of compression flow stress curve and a convex shape for the curve obtained in tension. I-ECAP processing led to suppression of this effect when route $\mathrm{B}_{\mathrm{C}}$ (Fig. 5c) was used but the tension-compression anisotropy was still observed for route A (Fig. $5 d)$.

a)
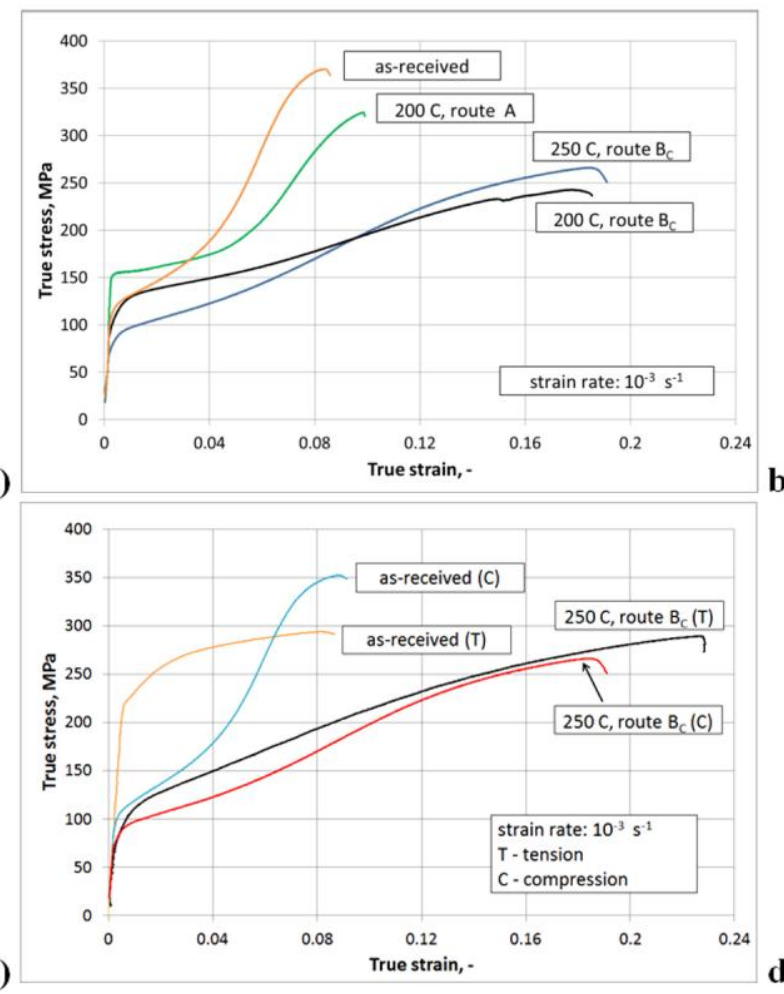

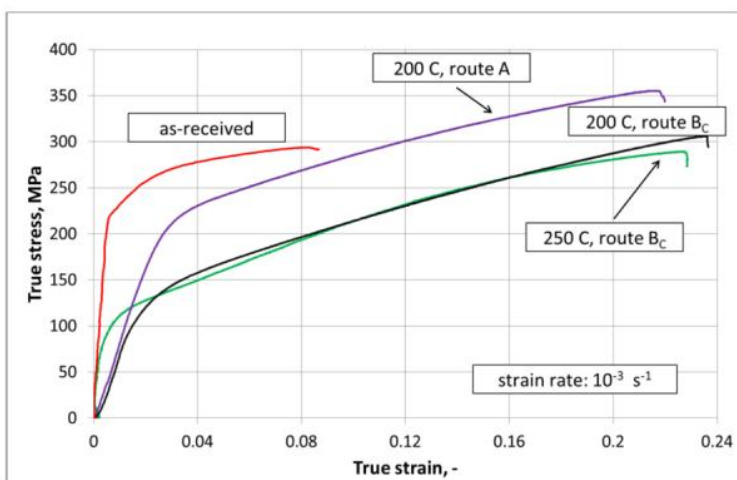

b)

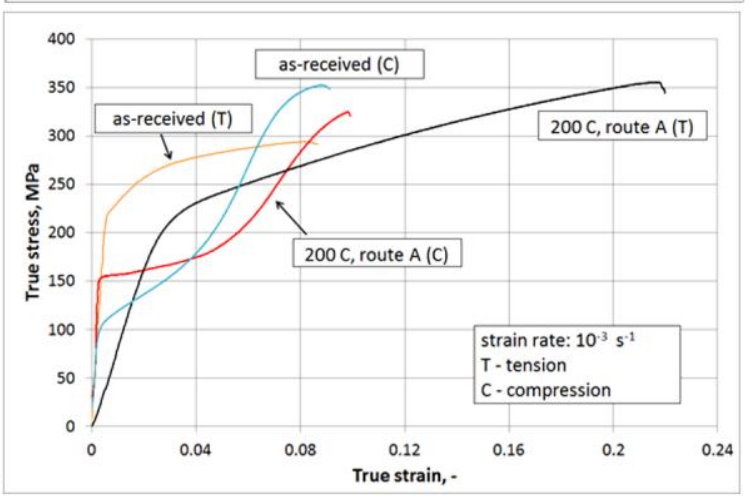

Fig. 5: Compressive (a) and tensile (b) flow stress curves obtained for as -received and I-ECAPed samples; tension-compression anisotropy observed for samples processed by routes $\mathrm{B}_{\mathrm{C}}(\mathrm{c})$ and $\mathrm{A}(\mathrm{d})$.

The results of mechanical tests indicate that grain refinement achieved by lowering processing temperature from $250{ }^{\circ} \mathrm{C}$ to $200{ }^{\circ} \mathrm{C}$ in the last two passes of route $\mathrm{B}_{\mathrm{C}}$ (Fig. $4 \mathrm{a}$ and $4 \mathrm{~b}$ ) has not affected mechanical properties (Fig. 5a). Strength and ductility of billets processed at different temperatures were very similar in tension and in compression (Fig. 5c). The conclusion is drawn that grain size reduction from 6.2 to $2.6 \mu \mathrm{m}$ does not affect mechanical behaviour of magnesium alloy processed by route $\mathrm{B}_{\mathrm{C}}$ of I-ECAP. The mechanism responsible for tension-compression anisotropy observed for route A (Fig. 5d) and 
suppressed using route $\mathrm{B}_{\mathrm{C}}$ is believed to be texture dependent. Taking into account similarities between ECAP and its incremental variant, that statement can be applied to conventional ECAP as well.

Strain rate sensitivity. In order to investigate strain rate sensitivity effect on billet shape during IECAP processing, FE simulations with strain rate dependant yield stress model were run. Johnson-Cook model was used to describe material behaviour during plastic deformation. The general idea of the model is that equivalent plastic strain rate is related to the ratio of the yield stress at nonzero strain rate to the static yield stress. The yield stress is given in [22]:

$$
\sigma=\sigma^{0}\left[1+C \ln \left(\frac{\dot{\varepsilon}^{p l}}{\dot{\varepsilon}_{0}}\right)\right],
$$

where, $\dot{\varepsilon}^{p l}$ is equivalent plastic strain rate given by Johnson-Cook model, $\dot{\varepsilon}_{0}$ is constant equivalent plastic strain rate corresponding to static deformation conditions, equal to $0.01, \sigma^{0}$ is static yield stress, $\sigma$ is yield stress at nonzero strain rate and $C$ is material constant.

Plane strain simulations with different $C$ parameters were performed in Abaqus/Explicit commercial FE software (ver. 6.10). Contact between a billet and dies is defined by Coulomb model with friction coefficient equal to 0.1 . Flow behaviour in static conditions is described by strain hardening model with initial yield stress $\sigma^{0}$ equal to $60 \mathrm{MPa}$. Modelling results for $C$ equal to $0,0.5$ and 1.0 were compared with billet shape after first pass of I-ECAP (Fig. 6). It was noticed that strain rate sensitivity can be estimated by measuring a distance between the upper flat surface and billet nose; the distance increases with the $C$ value rising. It is apparent from Fig. 6 that the billet shape prediction made by FE simulation is most accurate for $C$ equal to 0.5 . In Fig. 3a, the billet shape after four passes of I-ECAP shows that the distance between the billet upper surface and its nose is greater than $4.3 \mathrm{~mm}$ calculated with $C=0.5$. The conclusion can be drawn that strain rate sensitivity increases with consecutive passes of I-ECAP. In consequence of billet distortion, the material cannot fill the exit channel completely and this phenomenon escalates with increasing strain rate sensitivity.

a)

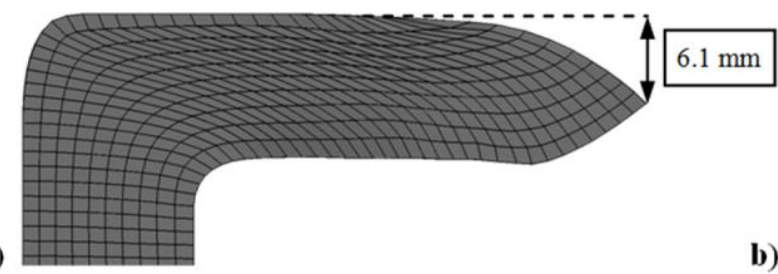

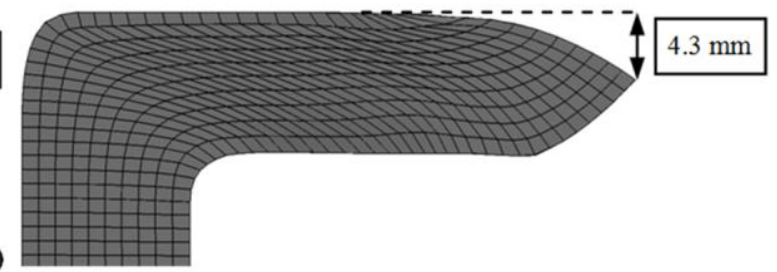

$1.3 \mathrm{~mm}$
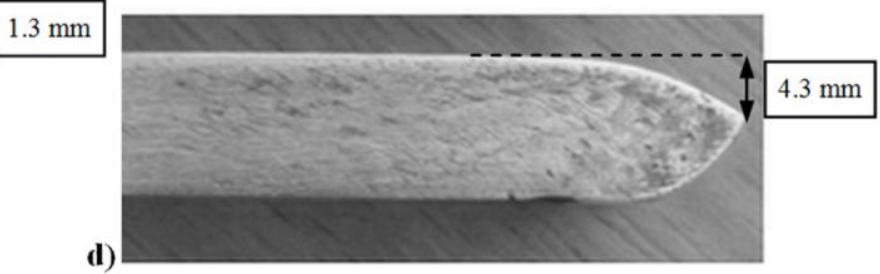

Fig. 6: Strain rate sensitivity effect on sample shape; FE modelling results for different $C$ values: 1.0 (a), 0.5 (b), 0 (c) and specimen after first pass of I-ECAP (d).

Distribution of equivalent plastic strain for the strain rate sensitivity parameter $C$ equal to 0.5 and 0 is shown in Fig. 7a. Strain profile along a transverse path is plotted in Fig. 7b. Strain localization is observed for the strain rate sensitive material while more uniform strain distribution is characteristic for rate 
independent flow. Plastic strain at the upper surface of the billet is smaller in both cases due to a punch profile curvature. Starting from $2 \mathrm{~mm}$ below the upper surface, strain value for $C=0$ equals $1.2 \pm 0.05$. When $C$ is increased to 0.5 , the strain distribution is less uniform. The maximum value 1.4 occurs $2-3 \mathrm{~mm}$ below the upper surface and falls down to 1.1 at the bottom surface.

a)

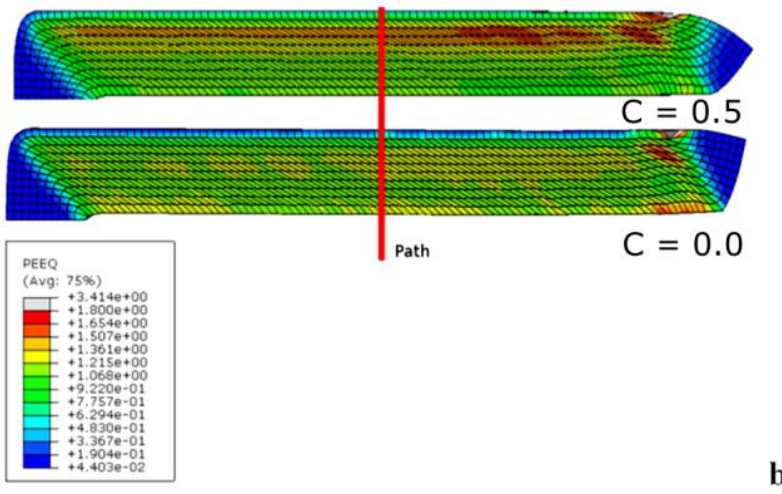

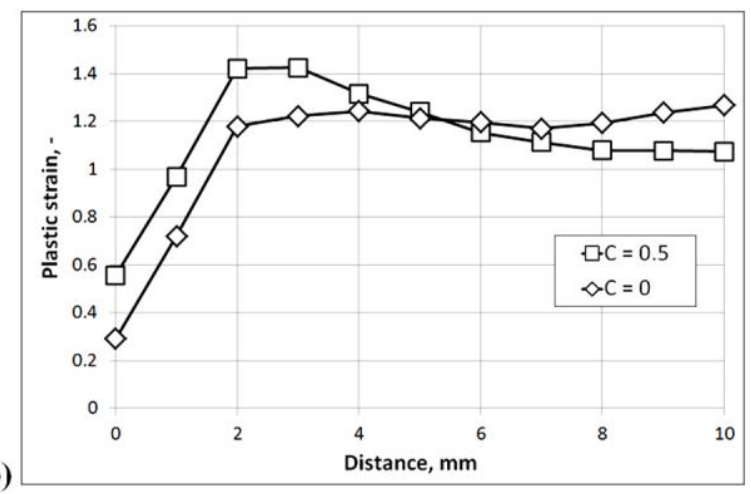

b)

Fig. 7: Equivalent plastic strain distribution for $C=0.5$ and $C=0$ (a) and strain profile along a transverse path (b).

Plastic anisotropy. Billet distortion after processing by route $\mathrm{B}_{\mathrm{C}}$ presented in Fig. $3 \mathrm{a}$ and $3 \mathrm{~b}$ indicates that flow behaviour cannot be described using a 2D analysis. Therefore, a three-dimensional FE model of I-ECAP was developed in order to find an explanation for observed cross-sectional asymmetry (Fig. 8a) and flow lines on the bottom surface (Fig. 8b). It was assumed that non-uniform strain distribution in the billet (Fig. 7) leads to non-uniform mechanical properties. After the first pass of I-ECAP, the maximum strain is localised $2 \mathrm{~mm}$ from the upper surface. Thus, it can be concluded that an upper part of the billet exhibits different mechanical properties from the lower part. Higher strain introduced in the centre of the upper part results in a smaller grain size. It favours formation of high angle grain boundaries that facilitate diffusion processes [21] and lower the force needed to deform material at elevated temperature. This effect can be observed when comparing the load readings from first and fourth pass of I-ECAP; it is clear that force is reduced with subsequent passes (Fig. 3d). Therefore, after the first pass the upper part of the billet is 'softer' than the lower one, assuming deformation at an elevated temperature. Rotation by $90^{\circ}$ changes the softer/harder orientation from upper/lower to right/left. In other words, properties near the left side wall of the die are different from properties near the right one. It explains why distortion is observed only when rotation is applied and is not seen for route A.

In order to verify the presented theory, FE simulations were run using an anisotropic material definition. Billet was divided into two parts of the same volume by a plane parallel to the extrusion direction. Different strain hardening material models were ascribed to each part. After rotation by $90^{\circ}$, the right part had lower yield stress than the left one due to strain inhomogeneity created during the previous pass. The FE results showed that the proposed approach explains the occurrence of flow lines on the billet bottom surface but cannot predict the gap in the billet corner (detail A in Fig. 8a). Therefore, it was proposed that the two parts of the billet exhibit different yield stress dependence on strain rate; equation (1) was used to describe this relation. It was assumed that the left part had higher strain rate sensitivity $(C=2)$ than the right one $(C$ $=0.1$ ). The proposed model was capable of predicting a gap in the billet corner (detail A' in Fig. 8c) as well as flow lines on the billet surface (Fig. 8d). 
a)

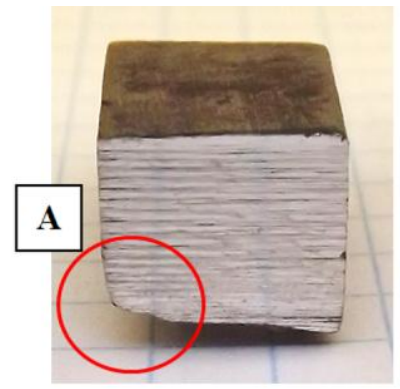

b)

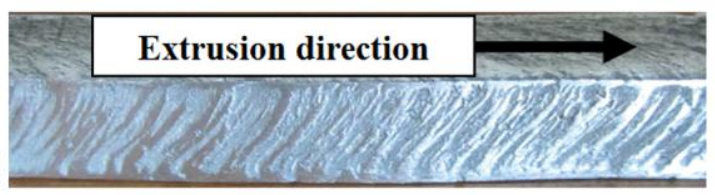

c)

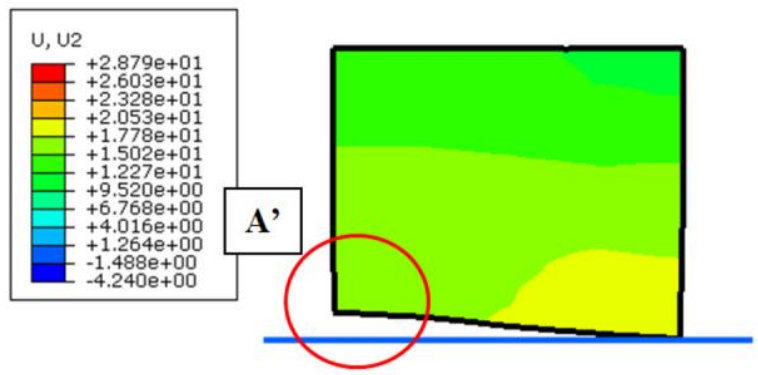

d)

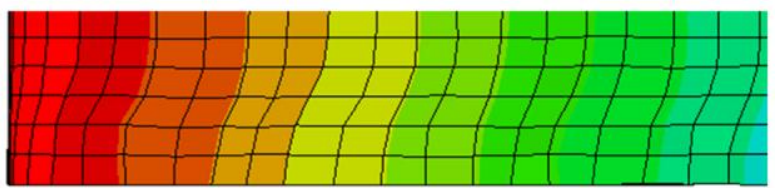

Fig. 8: Billet processed by route $B_{C}$ of I-ECAP: cross-section view (a) and a bottom surface with flow lines (b); corresponding FE simulation results of displacement in the transverse cross section (c) and along the extrusion direction (d).

\section{Conclusions}

Route effects on grain refinement efficiency, mechanical properties and billet shape in I-ECAP have been studied. Experiments were conducted using routes $\mathrm{A}$ and $\mathrm{B}_{\mathrm{C}}$ at $250{ }^{\circ} \mathrm{C}$ and $200{ }^{\circ} \mathrm{C}$. Two- and threedimensional $\mathrm{FE}$ simulations were performed in order to find explanation for observed billet distortion when processing using route $\mathrm{B}_{\mathrm{C}}$.

It is concluded that grain refinement in AZ31B is controlled mainly by temperature. In contrast, mechanical properties in tension and compression are not dependent on the mean grain size but on a processing route. Rotation by $90^{\circ}$ after subsequent passes results in suppression of tension-compression anisotropy observed initially for hot extruded rod. Billets processed by route A exhibit higher strength in tension comparing to route $\mathrm{B}_{\mathrm{C}}$ but tension-compression anisotropy remains as in the initial state. Mechanical properties are believed to be controlled by texture development rather than grain refinement.

Distortion of the billet cross section was observed during I-ECAP following route $\mathrm{B}_{\mathrm{C}}$. The material does not fill the exit channel completely and distinctive flow lines are observed on the bottom surface of the billet. This behaviour is explained by inhomogeneous strain rate sensitivity, developed during consecutive passes of I-ECAP and revealed due to billet rotation. Results of FE simulations confirmed that proposed model is capable of predicting the observed phenomena.

\section{Acknowledgements}

Financial support from Carpenter Technology Corporation is kindly acknowledged.

\section{References}

[1] B.L. Mordike, T. Ebert, Magnesium. Properties - applications - potential, Materials Science and Engineering A 302 (2001) 37-45.

[2] V.M. Segal, V.I. Reznikov, A.E. Drobyshevskiy and V.I. Kopylov, Plastic metal working by simple shear, Russian Metallurgy 1 (1981) 115-123 (Engl. Transl.). 
[3] J. Jiang, A. Ma, Bulk ultrafine-grained magnesium alloys by SPD processing : Technique, Microstructures and Properties, in: F. Czerwinski, Magnesium Alloys - Design, Processing and Properties, InTech, 2011, ISBN: 978-953-307-520-4.

[4] A. Rosochowski, L. Olejnik, FEM simulation of incremental shear, in: E. Cueto, F. Chinesta, Proceedings of the 10th International Conference on Material Forming, Esaform 2007, April 18-20, 2007, Zaragoza, Spain, American Institute of Physics 907 (2007) 653-658.

[5] A. Rosochowski, L. Olejnik, Incremental equal channel angular pressing for grain refinement, Materials Science Forum 674 (2011) 19-28.

[6] L. Olejnik, A. Rosochowski, M. Richert, Incremental ECAP of plates, Materials Science Forum, 584-586 (2008) 108-13.

[7] A. Rosochowski, M. Rosochowska, L. Olejnik, B. Verlinden, Incremental equal channel angular pressing of sheets, Steel Research International 81 (2010) 470-73.

[8] A. Rosochowski, L. Olejnik, M. Richert, Double-billet incremental ECAP, Materials Science Forum 584-586 (2008) 139-44.

[9] Y. Wu, I. Baker, An experimental study of equal channel angular extrusion, Scripta Materialia 37 (1997) 437-42.

[10] V.M. Segal, Equal channel angular extrusion: from macromechanics to structure formation, Materials Science and Engineering A 271 (1999) 322 - 333.

[11] R.B. Figueiredo, P.R. Cetlin, T.G. Langdon, Stable and unstable flow in materials processed by equal-channel angular pressing with an emphasis on magnesium alloys, Metallurgical and Materials Transactions A 41A (2009) 778-786.

[12] R. Lapovok, L.S. Toth, A. Molinari, Y. Estrin, Strain localisation patterns under equal-channel angular pressing, Journal of the Mechanics and Physics of Solids 57 (2009) 122-136.

[13] R.B. Figueiredo, P.R. Cetlin, T.G. Langdon, The processing of difficult-to-work alloys by ECAP with an emphasis on magnesium alloys, Acta Materialia 55 (2007) 4769-4779.

[14] P.R. Cetlin, M.T.P. Aguilar, R.B. Figueiredo, T.G. Langdon, Avoiding cracks and inhomogeneities in billets processed by ECAP, Journal of Materials Science 45 (2010) 4561-4570.

[15] Y. Estrin, R. Hellmig, Improving the properties of magnesium alloys by equal channel angular pressing, Metal Science and Heat Treatment 48 (2006) 504-507.

[16] K. Xia, J.T. Wang, X. Wu, G. Chen, M. Gurvan, Equal channel angular pressing of magnesium alloy AZ31, Materials Science and Engineering A 410-411 (2005) 324-327.

[17] S. Seipp, M.F.-X. Wagner, K. Hockauf, I. Schneider, L.W. Meyer, M. Hockauf, Microstructure, crystallographic texture and mechanical properties of the magnesium alloy AZ31B after different routes of thermo-mechanical processing, International Journal of Plasticity 35 (2012) 155-166.

[18] W.J. Kim, C.W. An, Y.S. Kim, S.I. Hong, Mechanical properties and microstructures of an AZ61 Mg alloy produced by equal channel angular pressing, Scripta Materialia 47 (2002) 39-44.

[19] M.R. Barnett, Z. Keshavarz, A.G. Beer, D. Atwell, Influence of grain size on the compressive deformation of wrought Mg-3Al-1Zn, Acta Materialia 52 (2004) 5093-5103. 
[20] R.B. Figueiredo, Z. Szaraz, Z. Trojanova, P. Lukac, T.G. Langdon, Significance of twinning in the anisotropic behavior of a magnesium alloy processed by equal-channel angular pressing, Scripta Materialia 63 (2010) 504-507.

[21] T. Fujita, Z. Horita, T.G. Langdon, Using grain boundary engineering to evaluate the diffusion characteristics in ultrafine-grained $\mathrm{Al}-\mathrm{Mg}$ and $\mathrm{Al}-\mathrm{Zn}$ alloys, Materials Science and Engineering A 371 (2004) 241-250.

[22] ABAQUS ver. 6.10 documentation. 